\title{
Improvement of the Performance and Aging Characteristics of Color Plasma Displays by Using a Co-Evaporated Protecting Layer
}

\author{
（共蒸着保護層を用いたカラープラズマディスプレイの発光特性の改善とエージング特性）
}

Kunio Yoshida ${ }^{\dagger}$, Yuichi Harano ${ }^{\dagger \dagger}$ (member), Heiju Uchiike ${ }^{\dagger}$ (member) and Hiroyasu Hashimoto ${ }^{\dagger}$

\begin{abstract}
This work shows that the application of a $\mathrm{MgO}$ and $\mathrm{MgF}_{2}$ co-evaporated protecting layer to a combination of transmissive and reflective phosphor type color PDPs improves the luminance and the luminous efficiency and the optimum composition of the co-evaporated layers is $24 \% \mathrm{MgO}$ and $76 \% \mathrm{MgF}_{2}$. This work also confirms that the sustaining voltage and life of reflective phosphor type color PDPs with the co-evaporated protecting layer are almost the same as those with a MgO single protecting layer. The sustaining voltage of combination of transmissive and reflective phosphor type color PDPs, however, is higher than that of reflective phosphor type color PDPs. It is probable that sustaining voltage can be decreased by thinning the thickness of the phosphors.
\end{abstract}

Key words : ac-PDP, Protecting material, Co-evaporating layer, Combination of transmissive and reflective phosphor type color PDPs, Vacuum ultraviolet rays of $147 \mathrm{~nm}$

\section{Introduction}

The luminescence from phosphor in color ac PDPs is due to the excitation by vacuum ultraviolet rays of 147 $\mathrm{nm}$ from Xe. The latest electrode structure of the surface-discharge ac PDPs applies the reflective type of phosphor layer which is deposited on the barrier ribs and rear substrate as shown in Fig. 1 (a ). The expansion of the deposited area of phosphors is one of the effective methods to improve luminance and luminous efficiency. It is clear that the concrete method to expand the area is to deposit phosphors on the front substrate as well as rear substrate and barrier ribs as shown in Fig. 1(b).

The deposition of phosphors on the front substrate by using the present technology is carried out the following procedure. First dielectric layer is formed on the front substrate, and then phosphors are deposited. Finally $\mathrm{MgO}$ is deposited on the phosphors to prevent from ion sputtering. The deposition of $\mathrm{MgO}$ protecting layer on

This paper was presented at IDW '97 on September 21, 1997

Received March 12, 1998 ; Revised July 2, 1998 ; Accepted September 10, 1998

$\dagger$ Department of Electronics, Hiroshima University

(4-1, Kagamiyama 1-chome, Higashi-Hiroshima-shi, Hiroshima 739-8527, Japan, TEL 0824-24-7640)

†† Hitachi Research Laboratory, Hitachi, Ltd.

(1-1, Omika-cho 7-chome, Hitachi-shi, Ibaraki 319-1292, Japan, TEL 0294-52-5111)

映像情報メディア学会誌 Vol. 52, No. 11, pp. 1707〜1712（1998）

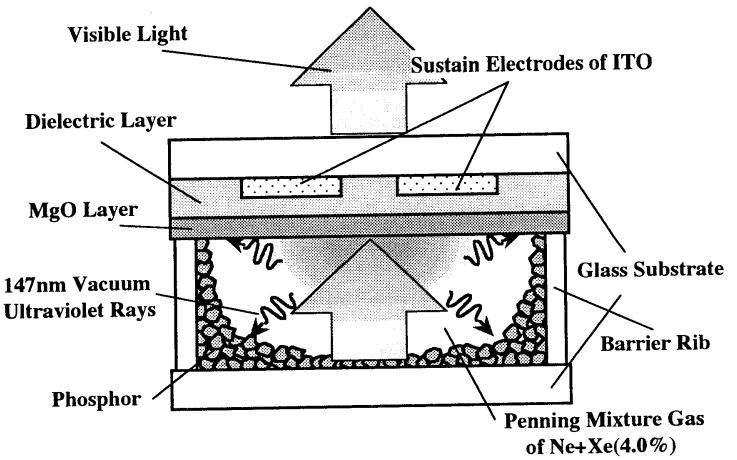

(a) Reflective phosphor type

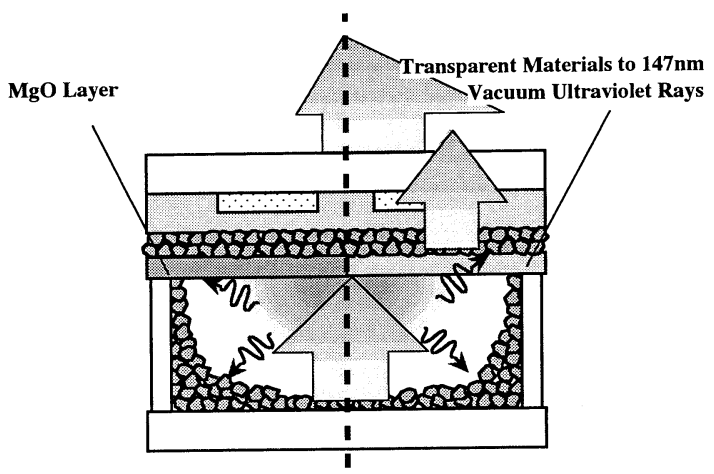

(b) Transmissive and reflective phosphor type The left of (b) is the case of MgO layer.

The right of $(b)$ is the case of trnsparent materials to $147 \mathrm{~nm}$ vacuum ultraviolet rays.

Fig. 1 The electrode structure of the surface-discharge ac PDP.

(177) 1707 
phosphors, however, does not result in to improve luminance and luminous efficiency, because $\mathrm{MgO}$ does not have transparent properties to ultraviolet rays around $147 \mathrm{~nm}$. Accordingly it is important to apply transparent materials to vacuum ultraviolet rays of 147 $\mathrm{nm}$ for protecting layer with the electrode structure show in Fig. 1 ( b ). In the present work, we decided to use $\mathrm{MgF}_{2}$ from the considerations of the transmissivity to $147 \mathrm{~nm}$, value of secondary electron emission yield, $\gamma_{i}$, and the surface potential among $\mathrm{MgF}_{2}, \mathrm{LiF}$, and $\mathrm{CaF}_{2}$.

It is proved that $\mathrm{MgF}_{2}$ itself is not able to be applied to protecting layer, because it has weak property against ion sputtering ${ }^{6}$. In order to overcome the difficulty in $\mathrm{MgF}_{2}$, the double protecting layer was proposed by one of the present authors ${ }^{4}$. The double protecting layer was fabricated by the deposition of $\mathrm{MgF}_{2}$ with a thickness of $5,000 \AA$ on the phosphors and $\mathrm{MgO}$ with a thickness of $400 \AA$ in turn. The application of the double protecting layer to Barrier-Electrode PDPs resulted in achieving the excellent value of 1,030 $\mathrm{cd} / \mathrm{m}^{2}$ and $1.0 \mathrm{~lm} / \mathrm{W}^{4)}$.

Transmissivity of $147 \mathrm{~nm}$ in the double protecting system is $30 \%$ even though a thickness of $\mathrm{MgO}$ is $400 \AA$. When $\mathrm{MgO}$ protecting layer is thinner than $400 \AA$, it becomes much weaker against ion sputtering and much shorter life time. Therefore, we decided to apply coevaporated protecting layer with $\mathrm{MgO}$ and $\mathrm{MgF}_{2}$ in order to have both transmissivity characteristic of $\mathrm{MgF}$ 2 and sputtering-proof characteristic of $\mathrm{MgO}$.

\section{Experimental}

\subsection{Co-evaporation method}

As shown in Fig. 2, $\mathrm{MgO}$ is deposited by electron beam evaporation method and $\mathrm{MgF}_{2}$ is deposited by heat resistance method, and the total thickness of $\mathrm{MgF}_{2}$ and $\mathrm{MgO}$ is $5,000 \AA$.

The evaporation velocity of $\mathrm{MgO}$ is constant, and the ratio of $\mathrm{MgF}_{2}$ to $\mathrm{MgO}$ is adjusted by changing evaporation velocity of $\mathrm{MgF}_{2}$.

\subsection{Testing panel}

Fig. 3 shows the electrode structure of testing panel of PDPs consisting of front substrate with phosphors, and rear substrate with two pairs of sustaining electrodes covered with dielectric layer and co-evaporated protecting layer. On a half of phosphor layer co-evaporated protecting materials is deposited; there is no protecting materials on the other half of phosphor layer. Luminance of co-evaporated protecting layer on phosphor layer and that of no protecting layer are measured and

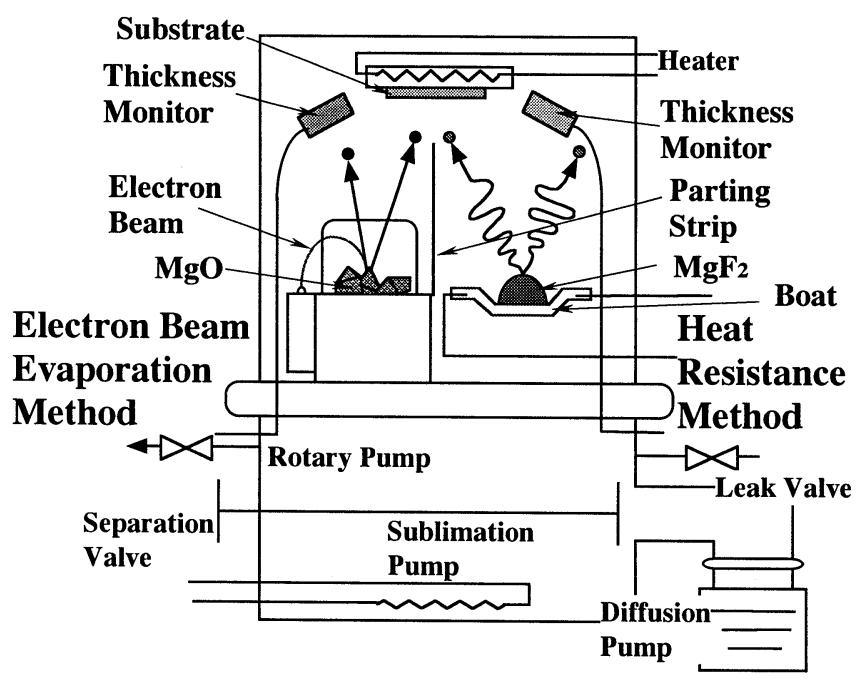

Fig. 2 Film deposition method by co-evaporation.

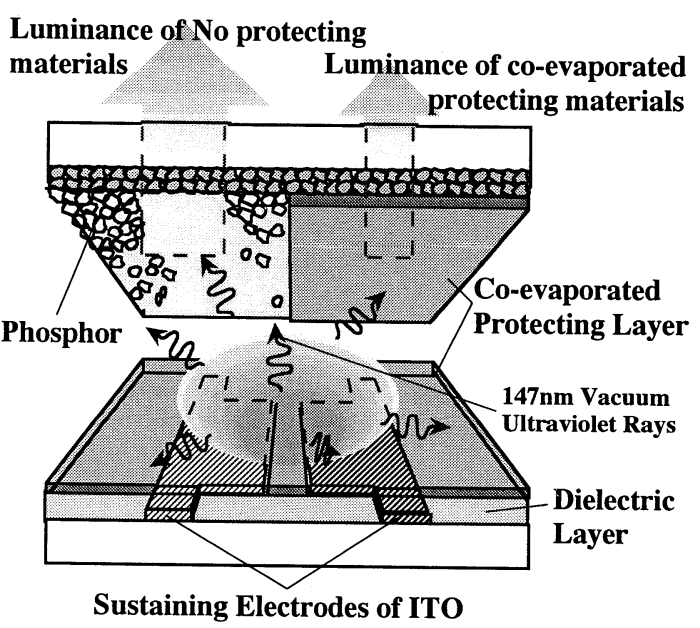

Fig. 3 Electrode structure of testing panel.

compared. Luminance and luminous efficiency were measured in the demountable tube under the condition of $4.0 \times 10^{4} \mathrm{~Pa}$ Penning mixture gas of $\mathrm{Ne}+\mathrm{Xe}(4.0 \%)$. Before the measurements testing panels were heated for 6 hours at the temperature of $350^{\circ} \mathrm{C}$ under the vacuum condition of $7.0 \times 10^{-6} \mathrm{~Pa}$.

\section{Results and Discussions}

Ion induced secondary electron emission yield, $\gamma_{i}$ is defined as value for secondary electron current divided by incident ion current. Fig. 4 shows the relationships between $\gamma_{i}$ and the composite ratio of co-evaporated layer. The composite ratio of co-evaporated layer was confirmed by the measurement of Rutherford Back scattering Spectroscopy (RBS). As shown in Fig. 4 (a), a value of $\gamma_{i}$ is a maximum at the composite ratio of $\mathrm{MgO}$ to $\mathrm{MgF}_{2}$ of $23 \%$. The surface potential is defined as a value of the voltage which corresponds to the 


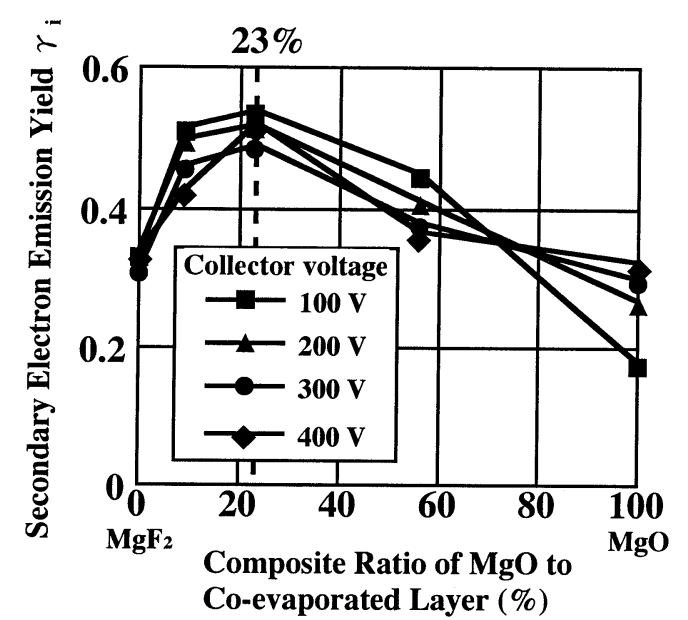

(a) Relationship between $\gamma_{i}$ and the composite ratio of $\mathrm{MgO}$

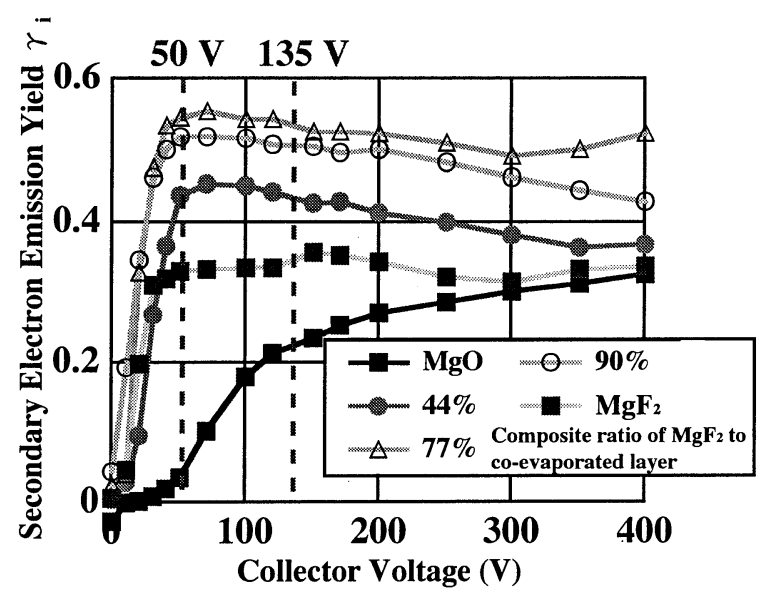

(b) Relationship between $\gamma_{i}$ and collector voltage

Fig. 4 Characteristics of $\gamma_{i}$.

saturated point in the characteristic curve of $\gamma_{i}$ versus collector voltage ${ }^{5}$. As shown in Fig. 4 ( b ), the surface potential of co-evaporated layer is lower than that of $\mathrm{MgO}$ single layer by $85 \mathrm{~V}$.

When resistance of dielectric material is high, the surface potential is able to be maintained to be high due to the ion bombardment and also the capability to accumulate wall charge is large during ac operation of PDPs. From the equivalent circuits shown in Fig. 5, the relationships among the sustaining voltage, $V_{s}$, the cell voltage, $V_{c}$, and the wall voltage, $V_{w}$, are defined as $V_{c}$ $=k V_{s}+V_{w}$, where $k=C_{o} /\left(C_{o}+2 C_{c}\right) . \quad C_{o}$ and $C_{c}$ are equivalent capacitance of dielectric layer and that of space, respectively. From these relationships $V_{w}$ should be increased to make the sustaining voltage, $V_{s}$, low. Therefore, the capability to accumulate wall charge is dominant factor whether PDPs are able to be operated by low $V_{s}$ and wide memory margin or not.

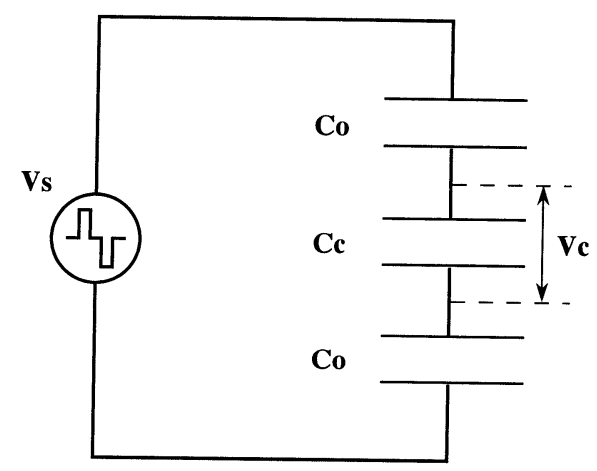

Fig. 5 The equivalent circuits of a PDP cell.

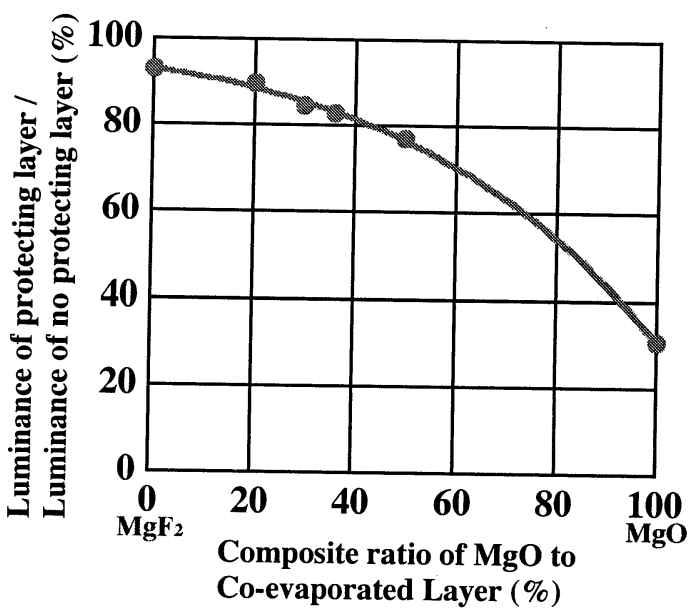

(a) Relationship between luminance and composite ratio of $\mathrm{MgO}$

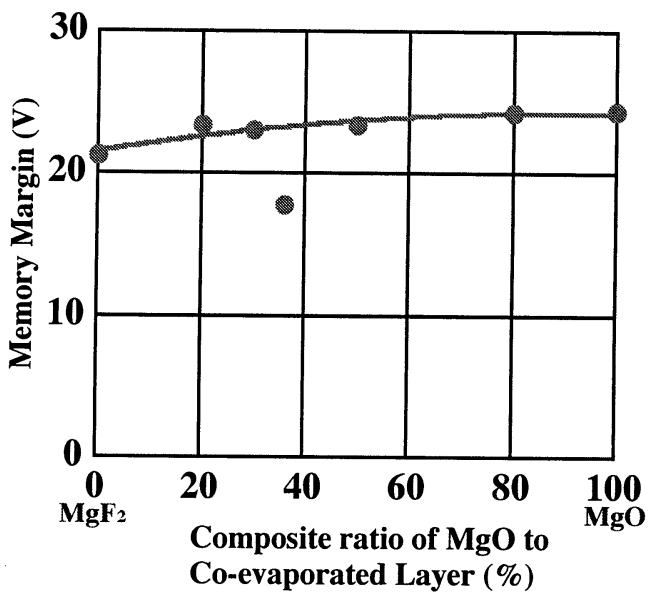

(b) Relationship between memory margin and composite ratio of $\mathrm{MgO}$

Fig. 6 Relationships between luminance and memory margin, and composite ratio of $\mathrm{MgO}$.

From the difference of luminance between coevaporated protecting layer on phosphor layer and no protecting layer, the relationships between the luminance and the composite ratio of $\mathrm{MgO}$ in co-evaporated protecting layer is shown in Fig. 6(a). Luminance decreases as the composite ratio of $\mathrm{MgO}$ increases. Fig. 
6 (b) shows the relationships between memory margin and the composite ratio of $\mathrm{MgO}$ in co-evaporated protecting layer. Memory margin increases as the composite ratio of $\mathrm{MgO}$ increases because minimum sustaining voltage decrease as the composite ratio of $\mathrm{MgO}$ increases. Memory margin of $\mathrm{MgO}$ single protecting layer is larger than that of $\mathrm{MgF}_{2}$ single protecting layer by $3 \mathrm{~V}$.

Memory margin is defined as the difference between the maximum sustaining voltage and minimum one and desired as large as possible in order to be operated without misaddressing in the whole display area. In the present paper the optimum composite ratio of $\mathrm{MgO}$ and $\mathrm{MgF}_{2}$ is obtained from cross point in Fig. 7 where Fig. 6(a) and 6(b) are combined. From Fig. 7, it is clear that the optimum composite ratio of $\mathrm{MgO}$ to coevaporated layer is $24 \%$.

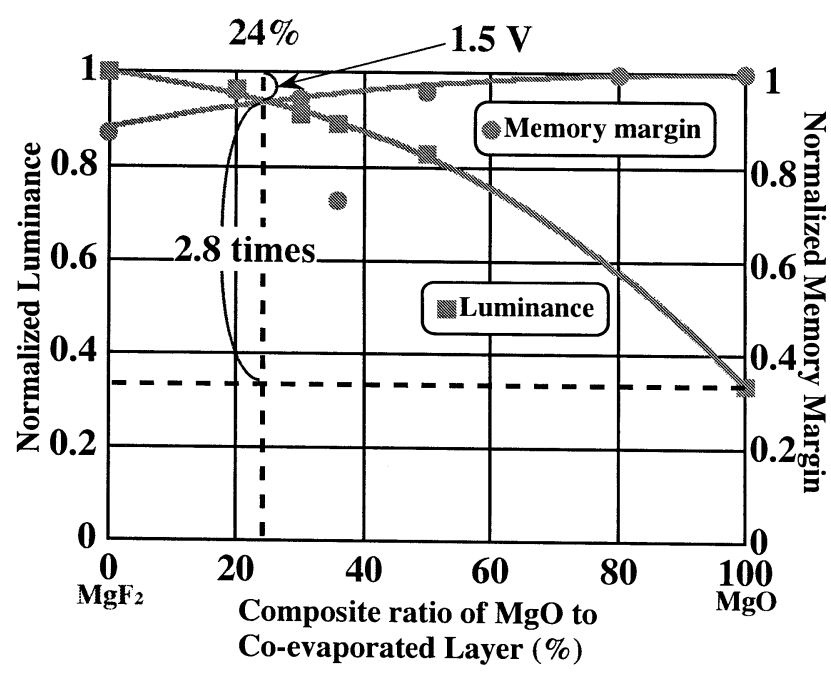

Fig. 7 Relationships between normalized luminance and memory margin, and composite ratio of $\mathrm{MgO}$.
By application of co-evaporation materials to protecting layer it is expected that luminance may increase 2 . 8 times and memory margin may decrease by $1.5 \mathrm{~V}$ with compared to $\mathrm{MgO}$ single protecting layer. Total luminance is estimated to be $950 \mathrm{~cd} / \mathrm{m}^{2}$ because of luminance of $350 \mathrm{~cd} / \mathrm{m}^{2}$ from front substrate and that of $600 \mathrm{~cd} / \mathrm{m}^{2}$ from rear substrate. For $R$ type PDPs (see appendix), a value of the measured luminance from rear substrate is $800 \mathrm{~cd} / \mathrm{m}^{2}$. Transmissivity of visible light through phosphor layer with a thickness of $10 \mu \mathrm{m}$ is $75 \%$. For $T+R$ type PDPs, a luminance from rear substrate is $800 \times 0.75=600 \mathrm{~cd} / \mathrm{m}^{2}$. The co-evaporated protecting layer is efficient to improvement of luminance for ac-PDPs.

Fig. 8 shows the aging characteristics for $R$ type PDPs whose composite ratio of $\mathrm{MgO}$ is $24 \%, 100 \%$ and $T+R$ type PDPs whose composite ratio of $\mathrm{MgO}$ is $24 \%$ in the demountable tube, respectively. $V_{s}$ is also defined as $\left(V_{f}+V_{s m}\right) / 2$, where $V_{f}$ and $V_{s m}$ are minimum firing voltage and minimum sustaining voltage, respectively. The exact life time for the present materials should be confirmed by measuring chipped-off PDPs. For convenience to evaluate a lot of protecting materials whether they are suitable or not from the point of view of a life time, we introduced a temporary life-time measurement system to operate for 500 minutes in the demountable measuring apparatus to compared with the $\mathrm{MgO}$ sample deposited by vacuum evaporated as a standard. It is sure that co-evaporated protecting layer in the composite ratio of $\mathrm{MgO}$ to $\mathrm{MgF}_{2}$ of $24 \%$ is the same life time as $\mathrm{MgO}$ single protecting layer.

Sustaining voltage of co-evaporated protecting layer is higher than that of $\mathrm{MgO}$ single protecting layer by 10 $\mathrm{V}$. Sustaining voltage of $T+R$ type PDPs is higher than

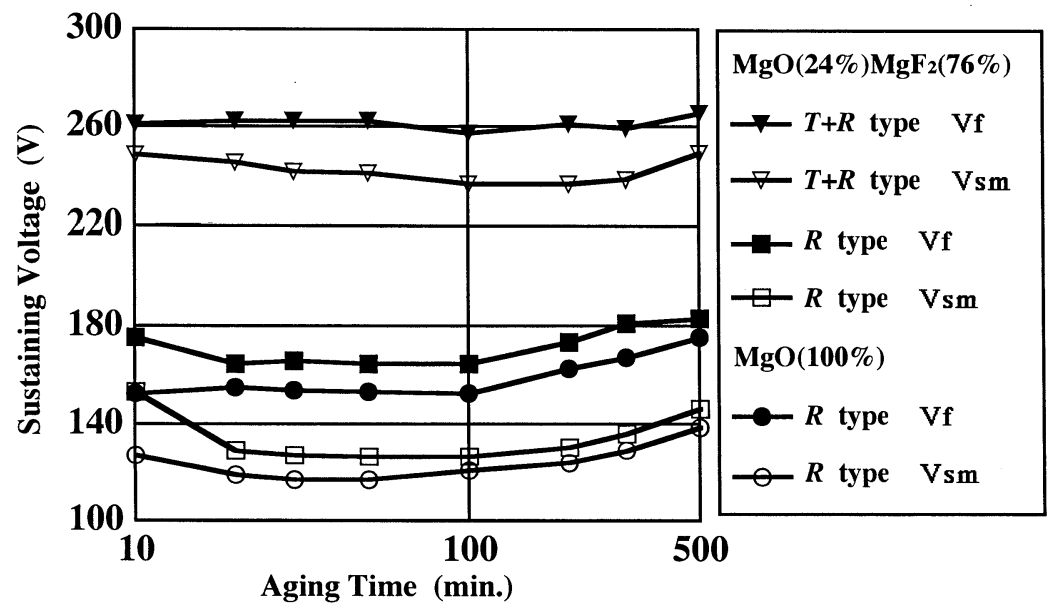

Fig. 8 Aging Characteristics of sustaining voltage at $\mathrm{MgO}$ composite ratio of $24 \%$ and $100 \%$. 


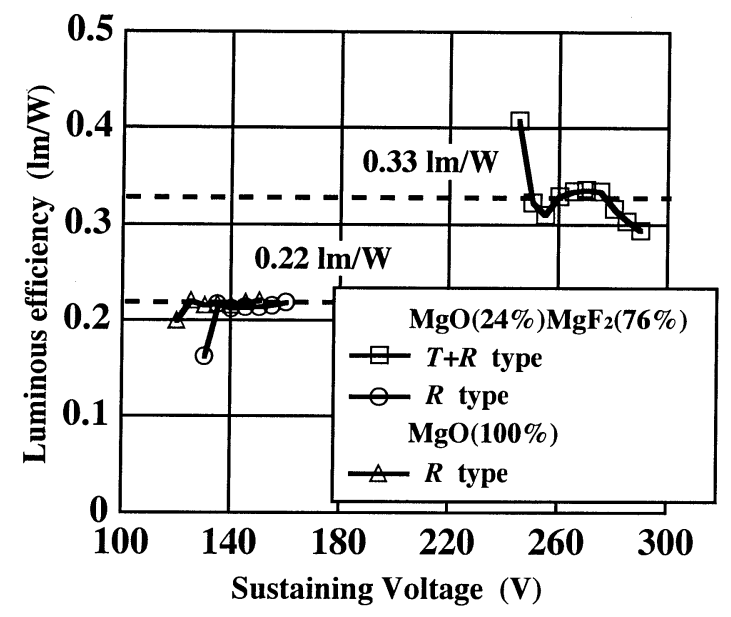

Fig. 9 Luminous efficiency of $T+R$ and $R$ types at $\mathrm{MgO}$ composite ratio of $24 \%$ and $100 \%$.

that of $R$ type PDPs by $100 \mathrm{~V}$. A value of $\gamma_{i}$ of coevaporated layer is larger than that of $\mathrm{MgO}$ layer. The surface potential of co-evaporated layer, however, is smaller than that of $\mathrm{MgO}$ layer. Experimental results concerning wall voltage show the tendency that the degree of decrease in $V_{s}$ due to a large value of $\gamma_{i}$ is smaller than that of decrease in $V_{s}$ due to the increase in wall charge, and vice versa.

It is suggested that the decrease of $V_{s}$ in $T+R$ type PDPs is caused by two reasons. When phosphor layer is inserted between dielectric layer and protecting layer, a value of Co shown in Fig. 5 decreases. The first one is that decrease of Co results in increases of $V_{s}$; the second one is that a value of $\gamma_{i}$ is supposed to be lowered for surface of phosphor layer, because the surface of the protecting layer is very unevenness due to the complicated shape of phosphor. It is well known that the secondary electron emission from rough surface is lowered due to preventing the secondary electrons from escaping out of the surface.

Fig. 9 shows Luminous efficiency for the same PDPs as Fig. 8. Luminous efficiency of $T+R$ type PDPs is 0 . $33 \mathrm{~lm} / \mathrm{W}$. That of $R$ type PDPs is $0.22 \mathrm{~lm} / \mathrm{W}$. Accordingly, luminous efficiency of $T+R$ type PDPs is 1.5 times comparing with that of $R$ type PDPs. From this result, it is expect that the real PDPs may have luminous efficiency of 1.5 times, too.

Fig. 10 shows the THEED (Transmission High Energy Electron Diffraction) pattern of co-evaporated layer whose composite ratio of $\mathrm{MgO}$ to $\mathrm{MgF}_{2}$ is $24 \%$. This result indicates that the present co-evaporated material is polycrystal because many rings are observed in the THEED pattern. Calculating from the radius of rings in the THEED pattern, values of the interplanar

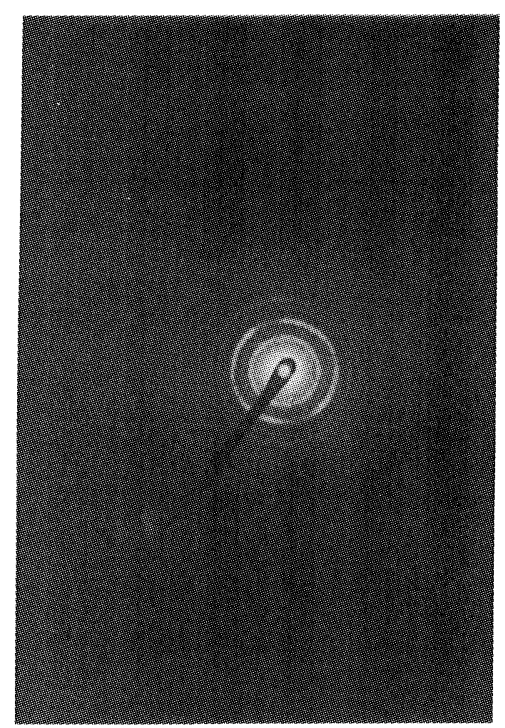

Fig. 10 THEED pattern of co-evaporated layer.

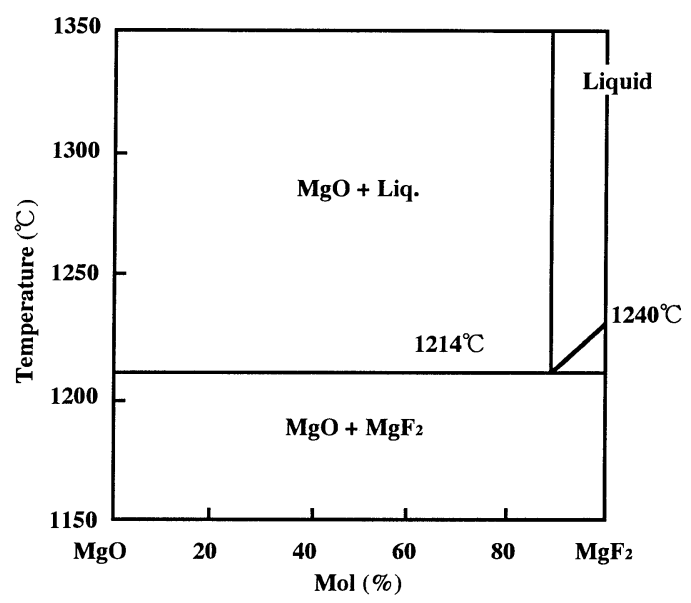

Fig. 11 Phase equilibrium diagram of the binary system $\mathrm{MgO}-\mathrm{MgF}_{2}$.

spacing are $3.122 \AA, 2.491 \AA, 2.230 \AA, 2.054 \AA, 1.697 \AA, 1$. $437 \AA, 1.361 \AA, 1.207 \AA$ and $1.110 \AA$ in order from inside ring, respectively. From the analyses of them by JCPDS card, it is proved that these interplanar spacings correspond to $\mathrm{MgF}_{2}(110), \mathrm{MgO}(111), \mathrm{MgF}_{2}(111), \mathrm{MgF}_{2}(210)$, $\mathrm{MgF}_{2}(211), \mathrm{MgO}(220), \mathrm{MgF}_{2}(301), \mathrm{MgO}(222)$ and $\mathrm{MgF}_{2}$ (222) in order from inside ring, respectively. The crystal structure of $\mathrm{MgO}$ and $\mathrm{MgF}_{2}$ are the rock-salt structure and $\mathrm{TiO}_{2}$ (rutile) structure, respectively. The observed results of the THEED suggest that the present co-evaporated material has a state of eutectic mixture.

Phase equilibrium diagram of the binary system $\mathrm{MgO}-\mathrm{MgF}_{2}$ is shown in Fig. 11, where is a state of eutectic mixture of $\mathrm{MgO}$ and $\mathrm{MgF}_{2}$, but no state of solid solution $^{7)}$. Fig. 11 supports our explanation to the THEED of the co-evaporated $\mathrm{MgO}$ and $\mathrm{MgF}_{2}$ described above. 


\section{Conclusion}

We measured luminance and aging characteristics for several kinds of composition ratios of co-evaporated layer. The optimum composite ratio of $\mathrm{MgO}$ and $\mathrm{MgF}_{2}$ to co-evaporated layer is $24 \%$ and $76 \%$, respectively. It is sure that co-evaporated protecting layer in the composite ratio of $\mathrm{MgO}$ to $\mathrm{MgF}_{2}$ of $24 \%$ is the same life time as $\mathrm{MgO}$ single protecting layer. Sustaining voltage of $T$ $+R$ type PDPs is higher than that of $R$ type PDPs by $100 \mathrm{~V}$ by depositing phosphors on the front substrate. Luminous efficiency of $T+R$ type PDPs is 1.5 times comparing with that of $R$ type PDPs.

The present co-evaporated protecting layer has a state of eutectic mixture. In this work, a thickness of phosphors on the front substrate is $10 \mu \mathrm{m}$. It is expected that sustaining voltage is decreased by thinning a thickness of phosphor layer and flattening phosphor layer. It is requested to use small size phosphors on the front substrate.

\section{Acknowledgment}

The present work is supported in a part by "Research for the Future" Program (JSPS-RFTF 96 R 12501) from the Japan Society for the Promotion of Science.

\section{〔References〕}

1) N. Seifert, et al.: "Sputtering of LiF films induced by low-energy $\mathrm{Ar}^{+}$impact”, Phy. Rev. B, Vol. 51, pp. 12202-12208, 1995

2) H. Lin, et al.: "Secondary Electron Emission Characteristics of Protecting Materials for Plasma Displays by Ion Bombardment", 3rd ASID Technical Digest, pp. 70-74, 1995

3) M. Kamiya, et al.: "Effects of protecting layer on Improvement of Luminance and Luminous Efficiency in Color AC Plasma Displays", ASIA DISPLAY '95 Digest, pp. 385-388, 1995

4) T. Sasaki, et al.: "Improvement of Luminance Efficiency in Barrier Electrode Color ac Plasma Displays by Using a Double Protecting Layer", SID '96 Digest, pp. 283-286, 1996

5) Y. Harano, et al. : "Secondary Electron Emission Characteristics of Protecting Materials for ac Plasma Displays by Ion Bombardment”, Technical Report of IEICE, Vol. 95, No. 526, pp. 43-48, 1996

6) Y. Harano, et al. : "Secondary Electron Emission Characteristics of Protecting Materials for ac-Plasma Displays", TECHNICAL REPORT OF IEICE, Vol. 96, No. 341, pp. 61-66, 1996

7) W. Hinz, et al.: "PHASE EQUILIBRIUM DATA FOR THE SYS TEM MgO- $\mathrm{MgF}_{2}-\mathrm{SiO}_{2}$ ”, THE AMERICAN MINERALOGIST, Vol. 45, pp. 1198-1205, November-December, 1960

\section{APPENDIX}

In Fig. 12, the structure of the left is " $T$ type PDPs" and that of the center is " $R$ type PDPs". We define that of the right as " $T+R$ type PDPs" as shown in this figure.

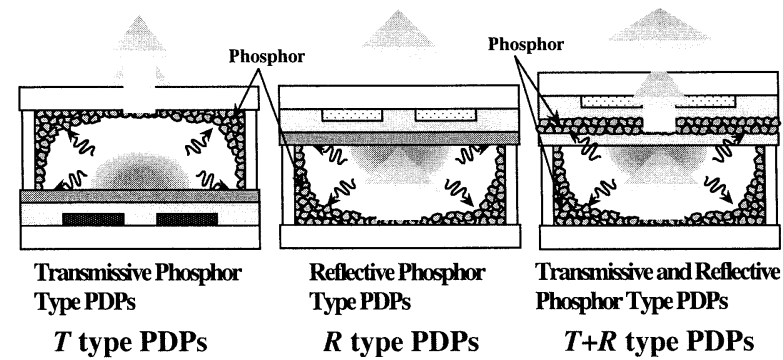

Fig. 12 Construction of the phosphor layerin a cell of color PDPs.

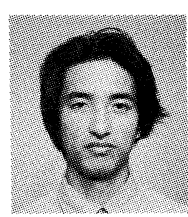

Kunio Yoshida Received the B. E. degree from Hiroshima University, Hiroshima, Japan in 1997. In 1997, he joined the graduate school of Hiroshima University. His study is on Protecting Layer of ac Plasma Display Panels. He is a student member of The Institute of Electronics, Information and Communication Engineers (IEICE).

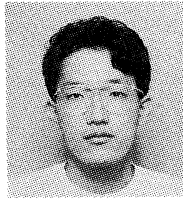

Yuichi Harano Received the B. E. and M. E. degree from Hiroshima University, Hiroshima, Japan in 1995, 1997, respectively. His study was on Protecting Layer of ac Plasma Display Panels. In 1997, he joined Hitachi, Ltd. Hitach Research Laboratory. He is a member of The Institute of Image Information and Television Engineers (ITE), The Institute of Electronics, Information and Communication Engineers (IEICE)

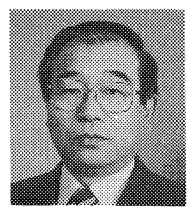

Heiju Uchiike Received B. E., M. E., and Ph. D degree from Tohoku University, Sendai Japan in 1962, 1964 and 1969, respectively. He joined Hiroshima University as an assistant professor in 1969 and was promoted to an associate professor in 1975 . Since 1969 he has researched and developed material and electrode structure of plasma displays. In particular, $\mathrm{MgO}$ was found as the most suitable protecting material for ac plasma displays by his works. He has promoted commercialization of color plasma displays by research and development on the surfacedischarge electrode structure since 1984 . He has researched on inorganic and organic electroluminescent displays and field emission displays in addition to color plasma displays. He was chairman of SID Japan Chapter from 1993 to 1994. He was program chairman of Japan Display '89 and conference chairman of Asia Display '95 and steering chairman of International Display Workshops '96 and 97. He was Vice-President of SID from 1996 to 1998. He is a member of The Institute of Image Information and Television Engineers (ITE), The Institute of Elec. tronics, Information and Communication Engineers (IEICE), Society of Japan Applied Physics, and The Society for Information Display (SID).

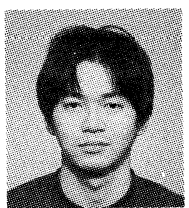

Hiroyasu Hashimoto Received the B. E. degree from Hiroshima University, Hiroshima, Japan in 1998. His study was on Protecting Layer of ac Plasma Display Panels. 